\title{
Evaluating food hubs: Reporting on a participatory action project
}

\author{
Erin Nelson ${ }^{a} *$ and Karen Landman ${ }^{b}$ \\ University of Guelph
}

Submitted August 28, 2019 / Revised June 6 and August 19, 2020 / Accepted August 31, 2020 /

Published online November 2, 2020

Citation: Nelson, E., \& Landman, K. (2020). Evaluating food hubs: Reporting on a participatory

action project. Journal of Agriculture, Food Systems, and Community Development, 10(1), 63-81.

https://doi.org/10.5304/jafscd.2020.101.018

Copyright $(2020$ by the Authors. Published by the Lyson Center for Civic Agriculture and Food Systems. Open access under CC-BY license.

\begin{abstract}
Food hubs create a range of economic, social, and environmental impacts through a wide variety of activities and programs. Evaluation of these impacts is important; however, many hubs lack the capacity (including time, resources, knowledge, and expertise) to do effective, ongoing evaluation work. This lack of capacity is exacerbated by the difficulties inherent in capturing the kinds of complex, multidimensional, context-specific impacts and

\footnotetext{
a * Corresponding author: Erin Nelson, Department of Sociology and Anthropology, University of Guelph; MacKinnon Building 615; 50 Stone Road E; Guelph, Ontario N1G 2W1 Canada; +1-519-824-4120 x53543; enelson@uoguelph.ca

${ }^{\mathrm{b}}$ Karen Landman, School of Environmental Design and Rural Development, University of Guelph; Landscape Architecture Building 105; 50 Stone Road E.; Guelph, Ontario N1G 2W1 Canada; +1-519-824-4120x53748; klandman@uoguelph.ca
}

\section{Funding Disclosure}

The authors would like to thank the Ontario Ministry of Agriculture, Food and Rural Affairs for funding this work. outcomes that many of these businesses and organizations strive to achieve. This paper reports on a participatory research project designed to develop a resource to support food hub evaluation efforts. It presents highlights from the guide that was created and discusses associated insights regarding the tensions and opportunities of food hub evaluation. We argue that food hubs need to be engaging in evaluation efforts, even in the face of significant resource constraints, as a means of strengthening individual entities and the sector as a whole. These efforts must be carefully aligned with

\section{Acknowledgments}

The authors would like to thank Elizabeth Nowatschin for her contributions to background research and toolkit design and Scott Cafarella for his work on the food hub organizational maps. We are also deeply grateful to the people working in the community food hub sector who shared their time and expertise with us, with the aim of supporting others engaged in work to build more sustainable local and regional food systems. Finally, thanks to three anonymous reviewers for their comments, which helped to strengthen this paper. 
a hub's stage of development and context-specific, multifunctional goals. They should also account for food hubs' emergent, dynamic, and adaptive nature. To that end, participatory evaluation methodologies that take a flexible, collaborative, action-oriented approach are especially relevant.

\section{Keywords}

Food Hubs, Evaluation, Participatory Research, Local Food, Community Development, Sustainable Food Systems

\section{Introduction}

Much has been written in recent years about the problematic nature of the conventional global food system. From an ecological standpoint, food production and transportation are two of the most significant sources of greenhouse gas emissions (Vermeulen, Campbell, \& Ingram, 2012). Furthermore, overuse of agrochemicals contributes to the contamination of soil and water resources (Food and Agriculture Organization of the United Nations [FAO], 2011), and extensive monocrop production threatens the biodiversity of ecosystems around the world (FAO, 2019). At the same time, small- and medium-scale farmers increasingly struggle to maintain the viability of their livelihoods (Berti \& Mulligan, 2016), while food security remains a serious problem even in the world's wealthiest nations (FAO, IFAD, UNICEF, WFP, $\&$ WHO, 2017). To make matters worse, a lack of food skills and knowledge contributes to high levels of food waste as well as diet-related disease (Allen, FitzSimmons, Goodman, \& Warner, 2003). One of many responses to challenges such as these has been the emergence of food hubs, which serve as a model for developing a kind of "infrastructure of the middle" (Stahlbrand, 2017) that can increase the viability of more localized food systems and, in the case of some hubs, also work toward broader goals related to social justice and ecological sustainability (see Blay-Palmer, Landman, Knezevic, \& Hayhurst, 2013; Clark et al., 2019).

The growing body of literature on food hubs highlights the diversity that exists within the sector, as a wide variety of actors employ different approaches, with considerable variation in the extent to which they challenge (or not) the con- ventional food system paradigm (see Berti \& Mulligan, 2016, Blay-Palmer et al., 2013; Cleveland, Müller, Tranovich, Mazaroli, \& Hinson, 2014; Levkoe et al., 2018; Perrett \& Jackson, 2015). This diversity produces some tensions, particularly as many food hubs grapple with how or if to engage in programs that may not be directly or immediately profitable, such as those that focus on social justice objectives (see Clark et al., 2019; Hoey, Fink Shapiro, \& Bielaczyc, 2018; Levkoe et al., 2018) and/or pursue environmental goals (see Cleveland et al., 2014; Franklin, Newton, \& McEntee, 2011). In spite of debates regarding the precise role that food hubs can or should play in a transition toward more sustainable food systems, it is clear that they are playing some role, as they create a range of economic, social, and environmental impacts through a wide variety of activities and programs (see Colasanti, Hardy, Farbman, Pirog, Fisk, \& Hamm, 2018; Jablonski, Schmit, \& Kay, 2015; O’Hara, 2017; Schmidt, Kolodinsky, DeSisto \& Conte, 2011). As we will elaborate upon in this paper, measuring such impacts is important; however, doing so effectively requires substantial resources (including time, money, knowledge, and expertise) that hubs often do not possess. This lack of capacity is exacerbated by the difficulties inherent in capturing the kinds of complex, multidimensional, context-specific impacts and outcomes that many food hubs strive to achieve.

The disconnect between the importance of evaluating food hub efforts and the challenges inherent in doing that work created the impetus for the project presented in this paper. With funding from Ontario's Ministry of Agriculture, Food and Rural Affairs (OMAFRA), we conducted participatory research with food hubs in Canada and the United States with the goal of creating a resource that would support their ability to conduct evaluations of their businesses or organizations. This paper presents the results of that project, including highlights from the guide that we developed as well as insights we gained regarding the tensions and opportunities associated with food hub evaluation. We begin with a brief overview of the food hub sector, some explanation regarding why evaluation is so important for its future development and success, and an outline of relevant ideas drawn from 
the evaluation literature. Following that introduction, we describe our project methodology. We then present our research results organized into three main themes: (1) capacity considerations that food hubs should take into account when thinking about evaluation; (2) evaluation as a necessity for food hub success; and (3) the importance of going beyond basic financial metrics to capture more holistic stories about the multifunctional work that food hubs are doing and how that work is tied to the creation of more sustainable food systems. Finally, we discuss a number of tensions as well as opportunities associated with food hub evaluation. We argue that food hubs need to be engaging in evaluation efforts, even in the face of significant resource constraints, in order to improve their own operations and also garner continued public support for their work. These efforts must be carefully aligned with a hub's stage of development and context-specific, multifunctional goals and should also account for food hubs' emergent, dynamic, and adaptive nature. As such, one-size-fits-all templates and more traditional evaluation frameworks have somewhat limited applicability. Instead, participatory evaluation methodologies that take a flexible, collaborative, action-oriented approach offer especially significant potential for food hub evaluation.

\section{Background: What are Food Hubs and Why do They Need to be Evaluated?}

A recent literature review by Berti \& Mulligan (2016) discusses two broad approaches to food hub work: values-based agri-food supply chain management and sustainable food community development. The values-based supply chain end of the spectrum is primarily categorized by forprofit businesses and tends toward a supply-side approach. It is well-articulated by the much-used Barham, Tropp, Enterline, Farbman, Fisk \& Kiraly (2012, p. 4) definition of a food hub as "a business or organization that actively manages the aggregation, distribution, and marketing of sourceidentified food products primarily from local and regional producers to strengthen their ability to satisfy wholesale, retail, and institutional demand." By contrast, Berti \& Mulligan's (2016) sustainable community development model type is generally the domain of nonprofit organizations, and is more consistent with a definition of food hubs as "networks and intersections of grassroots, communitybased organisations and individuals that work together to build increasingly socially just, economically robust and ecologically sound food systems that connect farmers with consumers as directly as possible" (Blay-Palmer et al., 2013, p. 524). Irrespective of where on this typology a food hub might fit, Rose (2017) stresses the multidimensional character of the sector as a whole, arguing that food hubs generally "embrace a systemic understanding of food and farming that values its multidimensional and multi-beneficial character" (p. 233).

While establishing a precise, uniform definition of a food hub is challenging, one thing that is clear is that food hubs are on the rise. In the United States, the number of documented food hubs increased 300\% between 2007 and 2014 (NGFN, 2015 cited in Rose, 2017), and by 2017 almost 400 hubs were identified and targeted for the third iteration of a national food hub survey (Colasanti et al., 2018). The results of that survey found that 119 respondent hubs had gross annual revenues totaling US $\$ 235$ million and employed almost 2000 people, with $67 \%$ indicating that their operations were breaking even or making a profit (Colasanti et al. 2018). That same year, a food hub survey conducted in Ontario was completed by 125 respondents (Blay-Palmer, Nelson, Mount \& Nagy, 2018), again demonstrating the vibrancy of the sector in the North American context, and Rose (2017) suggests that, while in Australia food hubs are currently less prevalent, there is growing interest in adapting and adopting the model as part of growing that country's local food movement.

In the United States, the vast majority of food hubs include a combined focus on promoting human health, market access for small- and medium-scale farmers, fair prices for farmers, and sustainable agriculture within their mission statements, while more than half also work towards a variety of other goals, including racial equity and fair wages (Colasanti et al., 2018). Similarly, food hubs in Ontario reported top operational values to be locality, sustainable agriculture, profit, social justice, and community and civic engagement, and 
the benefits of their work ranged from increasing market access and employment opportunities for youth, to providing food education and food donations (Blay-Palmer et al., 2018). There are tensions inherent in working towards these varied goals within a system that remains largely governed by market principles, and this can push food hubs to prioritize economic concerns above social or ecological ones (see Clark et al., 2019; Hoey et al., 2018). However, while food hubs do need to maintain financial viability to survive, and not all hubs seek to challenge the conventional food system to the same extent, it is still clear that a significant degree of multifunctionality is a key characteristic of the food hub model (see LeBlanc, Conner, McRae, \& Darby, 2014).

The highly multifunctional nature of most food hubs does not lend itself well to simple assessment of impacts. Indeed, in spite of the sector's rapid growth in recent years, there has been relatively little work done to track the multidimensional impacts that food hubs are having on the communities and food systems within which they are embedded. Part of the challenge is that it can be difficult to determine what indicators should be tracked. As Matson \& Thayer (2013) explain: "Because of their adaptability in function, a variety of metrics might be applied to determine whether a particular food hub is a 'success'. No single measurement can be applied to all food hubs, as each must be measured by its success or failure in achieving its own underlying goals" ( $p$. 47). This issue is echoed in a Brislen, Barham, \& Feldstein (2017) report examining case studies of food hubs that have failed, as they highlight the logistical complexity inherent in trying to evaluate several different types of activities that may exist within one hub. However, although the multidimensional nature of the food hub sector presents a particular challenge, evaluating even one aspect of a hub's operation can also be difficult. For example, although food hub finances may be one of the most conventional indicators of viability or success, there have been few economic impact assessments of the sector (Jablonski et al., 2015) and there is no agreed-upon method for conducting such work (O'Hara \& Pirog, 2013). In addition to methodological challenges, food hubs also face capacity challenges that can constrain their ability to engage in effective (or any) evaluation work. Discussing food movement organizations more generally, Freedgood, Pierce-Quiñonez, \& Meter (2011) note that "food system professionals may not use assessment tools or may shun food systems planning as an unnecessary step in creating on-theground projects" (p. 98). Because many food hubs suffer from resource scarcity (see Stroink \& Nelson, 2013), they can find it difficult to dedicate resources to evaluation, preferring instead to invest in their "on-the-ground" efforts.

In spite of these challenges, a number of important efforts have been undertaken to evaluate the impacts of specific food hubs, and of the sector as a whole. Most notable has been a series of three surveys conducted in the United States that has tracked the progress of the food hub sector there (Colasanti et al., 2018; Fischer, Hamm, Pirog, Fisk, Farbman \& Kiraly, 2013; Hardy, Hamm, Pirog, Fisk, Farbman \& Fischer, 2016). The most recent iteration of that survey found that food hubs are: (1) contributing to the economy, for example by creating jobs; (2) supporting small- and mediumscale farmers in accessing markets and securing fair prices; and (3) supporting the triple bottom line, for example through programs that aim to improve human health and increase food access for marginalized populations (Colasanti et al., 2018). A survey conducted in Ontario yielded similar results, finding that food hubs allowed producers to diversify their production, access new markets, and hire more people, while also creating opportunities for youth employment, food donations, and food education programming (Blay-Palmer et al., 2018). In addition to these examples of larger-scale projects that assessed multiple food hubs across a wide jurisdiction, many individual food hubs also conduct at least some internal evaluation work, enabling them to participate in surveys such as those just mentioned. A number of resources have been made available in recent years to support these efforts, notably a Business Assessment Toolkit published by Wholesome Wave (Moraghan \& Vanderburgh-Wertz, 2014) and a series of publications from the U.S. Department of Agriculture (Matson, Thayer and Shaw 2015a; 2015b; Matson, Thayer and Shaw, 2016; McFadden et al., 2017). 
However, while useful, these resources have a heavy focus on business planning and financial assessment, leaving a gap with respect to measures of social and/or ecological impacts.

A salient example of an individual food hub evaluation that looked beyond financial indicators is presented by Schmidt et al. (2011) in their discussion of research conducted with Vermont's Intervale Food Hub. Of particular interest in this case study is the participatory methodology employed by the researchers, who explicitly sought to facilitate learning and action to contribute to the organization's development through their work (Schmidt et al., 2011). Such an approach is consistent with arguments regarding the complex, adaptive and emergent nature of food hubs (Stroink \& Nelson, 2013) and food systems more generally (Meter, 2010), and the related limitations of trying to assess their impacts in more traditional, linear, outcome-oriented ways. As Meter (2010) puts it: "What if we examined [food systems'] underlying dynamics, rather than limiting ourselves to measuring only performance or impact? What if we embraced the complexity of the moment, and moved beyond linear models?” (p. 23).

Notwithstanding the efforts outlined above to capture some sectoral as well as individual food hub impacts through a range of more conventional as well as participatory methods, the recent literature examining the food hub sector clearly communicates a need for increased attention to research and evaluation (see LeBlanc et al., 2014; Levkoe et al., 2018; Matson \& Thayer, 2013). For example, in discussing the results of a roundtable discussion with food hub researchers and practitioners from the U.S., Canada, and Australia, Levkoe et al. (2018) conclude that one of three key lessons learned is that there is a need for future research to help make the case for food hubs. Similarly, Matson and Thayer (2013) call for more systematic data collection on food hub impacts, and LeBlanc et al. (2014) argue that work is needed to "document, test, and share keys to [food hub] success in order to begin to develop a roadmap for development from nascence to maturity" (p. 134). This is consistent with findings by Stroink and Nelson (2013) that some food hubs are more able than others to adapt to changing circumstances and survive over the longer term, but further investigation is needed to understand why this is the case.

While research and evaluation are important for the food hub sector as a whole, tracking impacts and outcomes is also critical for the longterm viability of individual food hub operations. Without a strategic understanding of core competencies and capacity, it is easy for food hubs, particularly in their earlier stages, to stretch themselves too thin (Feldstein \& Barham, 2017; Stroink \& Nelson, 2013). As a result, it is imperative that food hub staff have the knowledge and capacity to track financial as well as other metrics (Feldstein \& Barham, 2017) and that they use these metrics to guide planning and decision-making regarding their own development (Brislen et al., 2017). The implications of a lack of clarity regarding a food hub's core activities and how to evaluate success (or lack thereof) have directly contributed to the failure of some operations (Brislen et al., 2017). Even if it does not directly contribute to a food hub's failure, a lack of evaluation makes it difficult to optimize efforts. Hoey et al. (2018) cite a food hub manager grappling with how challenging it is to ensure an organization does its best work: "Are there ways to morph so that I can actually do the work of the hub even better? That's a huge struggle..." (p. 53). As will be discussed below, effective implementation of robust evaluation strategies can help alleviate at least some of that struggle.

Using evaluation as a means to improve operational efficiency and efficacy is particularly necessary because, although it is sometimes assumed that food hubs will be financially self-sustaining within the first several years of operation, the reality is that many continue to rely on at least some degree of grant funding for longer periods of time (Colasanti et al., 2018; Rysin \& Dunning, 2016). Given the wide range of economic, social, and environmental benefits that food hubs create, there is a strong argument for public and/or foundation funding to be made available for their continued functioning (Hoey et al., 2018; Rysin \& Dunning, 2016). As Hoey et al. (2018) explain, grants and other debt-free capital "allow food hubs to experiment, take chances, and ... with flexibility ... time and space to make mistakes, to figure things out slowly" (p. 54). While this may be central to their 
long-term success, maintaining external funding without clear demonstration of impacts and outcomes is difficult if not impossible. Rather, it is essential "to ensure that governments recognize that public support for food systems interventions, such as food hubs, is likely to yield economic, public-health, environmental, and social returns on investment" (Hoey et al., 2018, p. 57, citing Roberts, 2014). Similarly, it is important for food hubs to be able to realistically assess their specific funding needs and timelines (Rysin \& Dunning, 2016).

In thinking about the ways in which food hub research and evaluation could or should be carried out in practice, some useful insights can be drawn from literature in the field of program evaluation, which can be defined as "the systematic collection of information about the activities, characteristics, and outcomes of programs to make judgments about the program, improve program effectiveness and/or inform decisions about future programming" (Patton, 2000, p. 426). While such assessments are often required by funding agencies, "beyond meeting such accountability requirements, evaluation provides a rich and strategic opportunity to learn more about what works and how; inform improvements to a program or an approach; optimize the use of community assets and resources; and enable the discovery and sharing of successes" (Newberry \& Taylor, 2014, p. 5). Although the two categories are not mutually exclusive, evaluation is sometimes thought of as being either formative or summative, focused more heavily on process or on outcomes, with the former associated most directly with ongoing program improvement and learning and the latter with identifying and understanding reasons for success or failure (see Briedenham \& Butts, 2005; Newberry \& Taylor, 2014).

Because of the high degree of dynamism, complexity and multifunctionality characteristic of many food hubs (see Blay-Palmer et al., 2018; Stroink \& Nelson, 2013), evaluation approaches that are participatory, collaborative, flexible, and process-oriented are especially relevant as they are explicitly designed to take into account such factors (see Crishna, 2007a; Fetterman, 1994; Ramírez \& Brodhead, 2013). One specific example of this general approach is developmental evaluation, wherein the goal is "tight integration between evaluators and program staff and use of data for continuous program improvements" (Fagen et al., 2011, p. 645) rather than summative assessment of so-called success or failure. The developmental evaluation framework emerged as a way to support adaptive learning in complex, innovative, and evolving initiatives (Gamble, 2008) and is intended to enable "a long-term, on-going process of continuous improvement, adaptation, and intentional change" (Patton, 1994, p. 317). Another model that is well-aligned with documented characteristics and needs of many food hubs is Utilization-Focused Evaluation which is a highly flexible, user-driven, multimethod process that aims to build an organization's capacity for data-informed decisionmaking (Ramírez \& Brodhead, 2013). This methodology can contribute to both formative and summative evaluation needs and can involve collection of multiple data types (e.g., quantitative and qualitative) for multiple purposes (e.g., attention to process, outcomes, cost-benefit analysis), all depending on the needs and priorities of the intended evaluation users (Patton, 2000). Notably, approaches such as these do not offer a uniform set of methods; rather, they stress the importance of developing and adapting methods to suit the context of a particular initiative, taking into account the perspectives and priorities of key stakeholders (Crishna, 2007b; Fetterman, 1994; Ramírez \& Brodhead, 2013). Specific evaluation tools can range from more traditional logic models and quantitative measures, to in-depth mixed methods case studies as exemplified by Schmidt et al. (2011) in their work with the Intervale Food Hub.

\section{Overview of Research Project and Methods}

The idea for the project presented here grew out of an understanding of food hubs that was developed through previous research on local food systems and food hubs in Ontario (see Blay-Palmer et al., 2013; Blay-Palmer et al., 2018; Nourishing Communities, 2015), and ongoing communication with actors who had participated in that work. Those projects used the relatively expansive Blay-Palmer et al. (2013) definition and, as such, we employed that same definition, choosing to explicitly refer to 
community food hubs as a means of highlighting our interest in hubs that included goals beyond just profit. The project was initially conceptualized in consultation with the Ontario Ministry of Agriculture, Food and Rural Affairs (OMAFRA) as well as representatives from a number of Canadian food hubs, and was designed to include these stakeholders as active collaborators throughout the process.

We collected data from 2013 to 2015; this involved four main components. Firstly, the project team conducted a literature review examining the relationship between food hubs and evaluation. This literature included scholarly papers along with policy documents, evaluation design materials and reports, and NGO as well as funder (e.g., foundations) resources and documentation. Much of the literature in the latter category was provided by collaborating organizations. Secondly, the primary author conducted in-depth, semistructured key informant interviews with representatives from five food hubs, three evaluation experts with experience working in the local and regional food sector, and five members of OMAFRA's local food working group. The food hubs were selected to include a range of organizational type (i.e., distributionfocused hubs and hubs focused on a broader range of social and ecological issues, hubs of different scales, nonprofit as well as for-profit hubs, and hubs that had been operating for different lengths of time). Topics covered in the key informant interviews included motivations for doing evaluation work; specific models and metrics used; how these models and metrics were developed and/or adapted; resources used for evaluation; strategies for securing resources; evaluation results and products; benefits and challenges of evaluation; and, finally, strategies for addressing challenges.

In addition to the key informant interviews, we conducted in-depth case studies of two hubs, both of which represented more mature organizations characterized by both a high level of complexity in their programming and demonstrated leadership in evaluation work. Each case study included multiple site visits, observation of operations, interviews, focus group discussions, and review of internal documents. The final method used was a collaborative review of the initial evaluation guide that was drafted by the authors based on a synthesis of results of the literature review, interviews, and case studies. The authors shared that draft with all research participants via email and requested feedback. Participants from each of the five participating food hubs provided feedback (via email and, in some cases, telephone call), as did a number of the other key informants. The lead author collated this feedback and incorporated it into an updated draft of the guide and, again, shared that with research participants. The authors waited until all participants expressed satisfaction with the guide before finalizing it.

\section{Results}

\section{Capacity Considerations for Food Hub Evaluation}

As already noted, the motivation to conduct this project came from an understanding - based on previous research and conversations with relevant stakeholders - that evaluation presented a challenge for existing food hubs, and this perception was borne out by the research process. All of the participating hubs, even those that were most mature and had relatively robust evaluation systems in place, found themselves grappling with capacity issues when it came to evaluating their work. Specifically, research participants talked about how limited time and funds, as well as a lack of knowledge and expertise, constrained their ability to do effective evaluation work. One hub representative suggested he "wouldn't even know where to begin, or have the time and resources to dedicate to [evaluation]." Another noted that "you just kind of put your head down and go about your business, but I think there's lots of stories that can be told about the work we do... and those stories aren't necessarily being told..." Yet another spoke about wanting to track how consumer attitudes about food might be shifting as a result of participating in the hub but felt that "I have no idea about how to do that."

Although the more mature hubs that participated in our project faced challenges with respect to their evaluation capacity, it was clear that the extent to which a food hub will be able to engage in evaluation work, and the kinds of evaluation it can and should do, are closely linked to the number of years it has been operating. Our research 
results suggest that it can take seven to ten years for a food hub to begin to demonstrate the kind of outcomes that may be associated with its vision. "When you're in that early stage of things ... you're just thinking about things like attendance [at events or activities] and return attendees. ... It takes a while to have the luxury to look at other impacts. In the beginning, our surveys were about how we can make an event that people will like and will come to. Now we've figured out that formula, so it's become about how is this changing your life, or what role does this play in your life." These insights from a food hub staff member underscore how important process-oriented (as opposed to outcome-oriented) evaluation is for supporting food hub development in the first several years. Such an approach takes into account the reality that "tracking program success is easier than tracking program impact. Changing people's habits ... is much harder and slower than getting them to go out and gather some information or learn more about something" (food hub staff).

In addition to the impact that a food hub's stage of development will have on its evaluation capacity, the structure of a food hub will, to some extent, dictate the type of evaluation that is possible and desirable. The manager of one of the forprofit food hubs that participated in this project summarized his perception of the difference between a for-profit and nonprofit food hub with respect to evaluation: "We wouldn't have been ready to have done any evaluation until [the sevenyear mark]. It takes a certain scale to start thinking about big picture things, and we're finally at that kind of scale. Before this point, it's just been a grind. I was driving myself for the first three years, whereas now I have staff that oversee that. Until you have that luxury, for a for-profit business, it would be very difficult [to do any evaluation work beyond basic finances]. For a nonprofit, maybe you could get a grant to do some evaluation, but for us this is the earliest point at which we would consider it." As this statement indicates, evaluation tended to be more important for nonprofit hubs, at least in the early years, given their needs to report to funders as well as seek continued funding sources. That said, even the most economically focused hubs tend to include at least some social or ecological considerations as part of their mandate. The most important consideration then for developing an evaluation strategy is not what specific areas to focus on tracking, but rather to ensure that the information tracked is in alignment with the hub's specific goals and vision.

While research participants did draw some distinctions regarding when and how food hubs would want to engage in evaluation depending on organizational maturity, structure, and goals, there was consensus that it is important to make evaluation as simple and resource-efficient as possible, and to make some effort to do it in some way, even if imperfectly. As one food expert explained, "it doesn't matter if you weren't doing evaluation from the beginning. ... It's never too late to start." In some cases, food hubs were doing evaluation without directly recognizing it as such. For example, one food hub manager explained: "We haven't really formalized an evaluation process. A lot of it is just through sort of informal meetings with member farmers. We brainstorm ideas over a case of beer, for example, and we gather a ton of really valuable information. Some of that gets recorded, though a lot of it is just in my head and gets implemented right away." Regardless of how formal or informal the approach, participants agreed that building evaluation into a food hub's daily operations was the easiest and most efficient way to ensure it gets done. One staff member suggested: "If you're hiring people, they need to know that $15 \%$ of their job is going to be evaluation and tracking. That needs to just be built into all positions. That expectation has to be set, and it becomes part of all the positions, instead of having to hire someone specifically to do it." Another important consideration was taking care in selecting the information to be tracked. 'You've got to pick three to five things" argued one food hub staff member, "because if you have hundreds of things, you're never going to get the data you want. And you have to stick by your decisions, so if someone asks you 'how many $x$ ?', and you're not measuring ' $x$,' you can be open in that conversation and say why you did the evaluation the way you did and why you don't have that data. You can offer to get it if it might be useful, but you need to know why you'd get it." 
Evaluation as Essential for Optimizing Operations and Communicating Impacts

All project participants clearly indicated that they considered evaluation an important component of their food hub's work and felt that it would contribute to the long-term success of their business or organization. As one food hub representative put it, evaluation "is not a want anymore; it's a need." The motivations for engaging in evaluation fell into two broad categories: optimizing operations and telling the story of a food hub's work.

There was a keen awareness of how developing and implementing a strong evaluation plan could help optimize a food hub's work by increasing clarity of vision and purpose, as well as creating opportunities for course corrections. From this perspective, evaluation was sometimes likened to using a map for navigation, with one food hub staff person noting: "It's really important to ... draw a line from where you are to where you want to be, and try to stay on that path as much as possible." In some cases, a strategic planning process was viewed as an essential foundation for evaluation efforts. During field visits to one food hub, staff members repeatedly gestured to a large poster on the boardroom wall that illustrated the organization's core mission and goals in a very simplified way. The manager of that hub explained how this version of the strategic plan was used to maintain a clarity of purpose: "I printed out the one page because we had so many meetings [in that room] and I wanted us to be able to keep our eyes on the high level points."

Research participants also stressed how evaluation results can create opportunities to improve the functioning of the food hub by demonstrating what is working well and what is not and enabling strategic decision-making. In the words of one food hub staff person: "Evaluating is really about: How do I improve the process, and how do I get enough information so that I can make decisions grounded in a good assessment of what's really going on." All of the hub representatives we spoke to indicated that they had, at one time or another, made some changes to their operations as a result of feedback received via formal or informal evaluation. In some cases, these changes were relatively minor, for example the timing of an activity or the format for a workshop; however, in other cases, evaluation results helped clarify the need for more significant course corrections such as the discontinuing of a particular program that was consuming limited hub resources without achieving the desired impact.

The second rationale that research participants expressed for engaging in evaluation work was that it helps them tell the story of what their food hub does and why their work matters, enabling them to track metrics and articulate impacts to a range of stakeholders. One food hub staff person described how having solid evaluation results helps her feel confident about securing future funding: "I like feeling confident. I like going into a meeting with a funder, or writing a grant, and knowing that I'm accurately representing the work we're doing. I like being confident that the impact we can demonstrate is real, and measurable, and repeatable." While current and potential funders are perhaps the most immediately obvious audience for the story of food hub impacts, they are certainly not the only one. Research participants also spoke about sharing evaluation results with customers, business partners, policy-makers, program participants, community members, and the general public. "One big benefit [of doing evaluation] is sharing your success" explained one food hub staff person, who went on to note: "I share our work with a lot of other organizations, so having some synthesis of what we do is super helpful in being able to outline what our impacts are."

In terms of the food hub sector's capacity to contribute to more systemic food system change, research participants identified policy-makers as an essential target audience for messaging about impacts. One research participant made the link between effective evaluation and the potential to influence policy very explicit: "The policy window is going to open in a discussion around food and we're hoping that we've got what we need to prove what works and push some stuff through. We're starting to get into the political fray and it's a whole new learning curve." With respect to this potential to influence public policy, some food hub staff also noted the importance of communicating their impacts to the general public in the hopes that they would then put pressure on elected officials to 
enact changes, for example to support local food processing infrastructure or public procurement programs.

\section{Looking at the Numbers but also Beyond Them} Implicit in this discussion regarding the importance of evaluating food hubs is the notion that impact measurement needs to be about more than just numbers and, specifically, about more than just a hub's profitability and direct economic impact. That said, research participants from both forprofit and nonprofit food hubs noted that tracking basic finances can be a useful starting point for thinking about evaluation. For example, they explained that tracking the dollar value of local food that is bought and sold through a hub is relatively easy. Indeed, across the hubs, there was a sense that "dollars are so easy to measure" (food hub manager) and that understanding financial viability was essential to the long-term success of a hub, regardless of structure.

While there was strong recognition regarding the importance of evaluating financial viability and tracking basic numbers such as local food bought and sold, all research participants agreed that capturing the multifunctional benefits of their food hubs was necessary in order to understand and communicate the full picture of their work. In the words of one food hub staff person: "if [a food hub] is judged by its ability to be financially sustainable over time and grow over time like a business - a straight up for-profit business - then it may not be catching all those other benefits that aren't captured in the bottom line but that are invaluable to changing the culture, or getting food to hungry people, or whatever the goal happens to be." Similarly, one hub staff person-who was trained as an accountant-suggested that food hubs would do best to measure investment-tooutput ratios as opposed to the more traditional profits versus losses as a means of elucidating the value achieved through public investment even in the face of possible financial "losses." In spite of this recognition, most of the hubs felt that they were falling short in these efforts to track their impacts more holistically. The manager of one of the most mature hubs, that had quite robust evaluation systems in place, explained the challenge: "If we're successful with the food hub it's not just that the food hub makes half a million dollars in food sales and returns that to the farms, but we're hoping that people are making different purchasing decisions outside of what we do. And we haven't really gotten all the way to [measuring] that, though we're starting to ..."

The specific multifunctional impacts that the food hubs in our study were aiming to achieve, and ideally measure, can be clustered into four general categories: achieving economic viability and development; increasing access to and demand for healthy local food; improving personal and community wellbeing; and enhancing ecological sustainability (Figure 1). As outlined in Figure 1, within each category we identified a number of specific goals, such as: creating jobs and increasing market access for small- and medium-scale businesses; increasing purchases of healthy local food and increasing food skills and literacy; improving selfconfidence in decision-making and increasing social connections and relationships.; and increasing biodiversity and increasing use of renewable energy. Each hub was not working towards all of the goals presented; rather, these goals reflect the range of desired outcomes that we encountered across participants.

These sample food hub outcomes appear in the evaluation guide as a menu of options designed to help hubs identify the ones that apply to their operations. They are accompanied by similar tables of common food hub activities and sample metrics to track the success of those activities (for more formative evaluation work), as well as a set of sample metrics to support the design of data collection tools that can be used as part of more summative evaluation efforts (Figure 2). Our initial hope had been to develop a more concise, and perhaps even uniform set of metrics and measures that could significantly reduce the time and effort required for food hubs to design and implement evaluation work; however, research results quickly and clearly demonstrated that the highly contextspecific nature of each hub did not lend itself well to such a prescriptive approach, but rather to something more flexible and process-oriented. One drawback of this approach is that the evaluation guide does not provide the kind of template that 
Figure 1. Common Outcomes that Community Food Hubs Want to Achieve (from Nelson \& Landman, 2015)

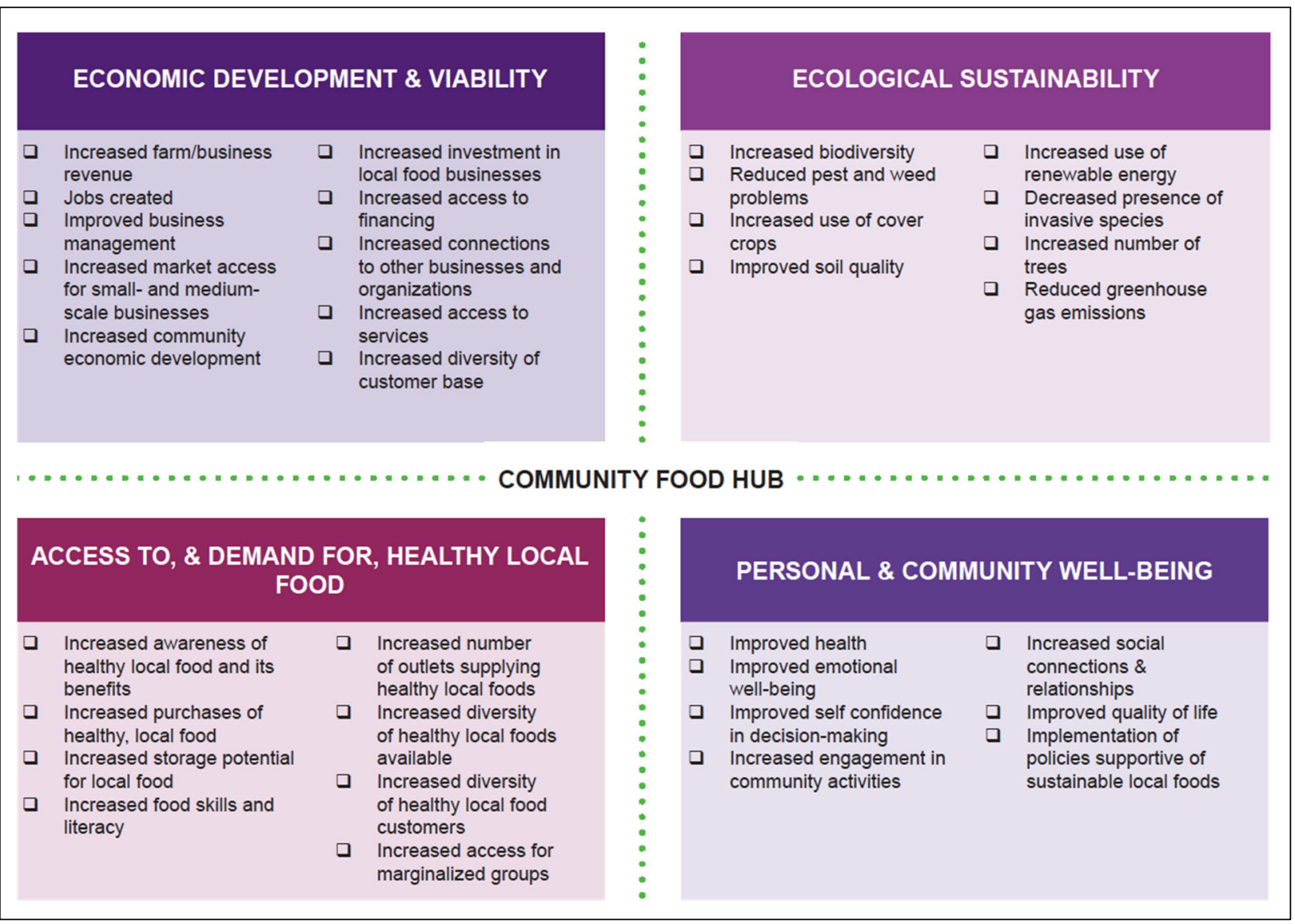

some food hub stakeholders may be interested in. Such a product would not have been applicable to the full spectrum of food hubs that we encountered through our research, including hubs with different organizational structures, operating at different scales, characterized by varying stages of development and levels of complexity, and focusing on a wide variety of goals and priorities. To accommodate this diversity, a collective decision was made that a process-oriented resource guide was most appropriate.

One final insight with respect to the importance of looking beyond basic finances in evaluating food hub activity is the way in which multiple research participants referred to an element of "magic" inherent in using evaluation results to paint an effective picture of a food hub's multifaceted impacts on society. One staff person explained: "You have to not worry about the societal change and proving it. From my perspec- tive, the connection between the stuff happening in your boxes [i.e., your food hub's activities] and the bigger societal change is magic and you explain it in a paragraph where you say 'we did this specific thing and these are our program numbers' but you don't claim you made the big societal impact. But then you can say 'there is this big problem and it's getting better and this is how our work contributes.' You have to paint that story and demonstrate that magic." This notion of magic was also used to describe the actual activities of a food hub organization, and the challenges associated with measuring the impacts of those experiences. In the words of one manager referring to a particularly successful community event organized by the hub: "We have done some things that are just a bit of magic" and "a key question is how you capture those things [in an evaluation]."

This concept of magic was closely related to the importance of storytelling as part of a food 


\section{Figure 2. Sample Outcomes and Associated Indicators for Community Food Hubs (from Nelson \& Landman, 2015)}

\begin{tabular}{|c|c|c|}
\hline \multirow{6}{*}{ 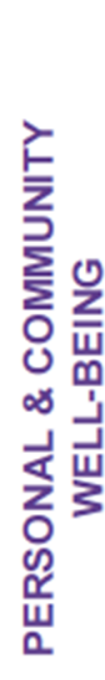 } & OUTCOME & SAMPLE INDICATORS \\
\hline & Improved health & $\begin{array}{l}\text { 口 Program participants' opinions regarding health } \\
\text { improvements }\end{array}$ \\
\hline & $\begin{array}{l}\text { Improved self confidence } \\
\text { in decision-making }\end{array}$ & $\begin{array}{l}\text { Program participants' opinions regarding improvements } \\
\text { in confidence }\end{array}$ \\
\hline & $\begin{array}{l}\text { Increased social } \\
\text { connections }\end{array}$ & $\begin{array}{l}\text { Number of new relationships formed through program } \\
\text { participation or involvement with organization }\end{array}$ \\
\hline & $\begin{array}{l}\text { Increased feeling of } \\
\text { community belonging }\end{array}$ & $\begin{array}{l}\text { Stories regarding sense of belonging from program } \\
\text { participants } \\
\text { Number of participants indicating an increased sense of } \\
\text { belonging }\end{array}$ \\
\hline & $\begin{array}{l}\text { Implementation of policies } \\
\text { supportive of sustainable } \\
\text { local foods }\end{array}$ & $\begin{array}{l}\text { Documentation of new policy initiatives that support } \\
\text { sustainable local foods }\end{array}$ \\
\hline 至 & OUTCOME & SAMPLE INDICATORS \\
\hline 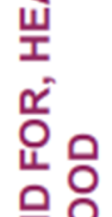 & $\begin{array}{l}\text { Increased awareness of } \\
\text { healthy local food and its } \\
\text { benefits }\end{array}$ & $\begin{array}{l}\text { Increased consumer knowledge about where to } \\
\text { purchase local food } \\
\text { Increased consumer knowledge about local food } \\
\text { benefits } \\
\square \text { Increased willingness to pay a premium for local foods }\end{array}$ \\
\hline$\underset{\Sigma}{z}$ & $\begin{array}{l}\text { Increased purchases of } \\
\text { healthy, local food }\end{array}$ & $\begin{array}{l}\text { Sales numbers for local food, especially fruits, } \\
\text { vegetables and other non-processed foods }\end{array}$ \\
\hline 㟧宁 & $\begin{array}{l}\text { Increased access for } \\
\text { marginalized groups }\end{array}$ & $\begin{array}{l}\text { Diversity of client or program participant population } \\
\text { Amount of food sold or distributed at reduced rates for } \\
\text { low income populations }\end{array}$ \\
\hline 我 & $\begin{array}{l}\text { Increased storage potential } \\
\text { for local food }\end{array}$ & $\begin{array}{l}\text { Square footage available at local food storage centres } \\
\text { Square footage of refrigerated storage space }\end{array}$ \\
\hline Uુ & $\begin{array}{l}\text { Increased food skills and } \\
\text { literacy }\end{array}$ & $\begin{array}{l}\text { Increased knowledge regarding food skills (e.g. } \\
\text { canning, } \\
\text { Increased knowledge about nutrition }\end{array}$ \\
\hline
\end{tabular}

hub's evaluation strategy and essential for, again, capturing the complex, multifunctional nature of the work. One food hub manager explained how a compelling narrative could be created drawing upon relatively small numbers and combining them with other data to create an effective story about a food hub's impact: "We can say 'we planted 35000 trees last year' and people nod, and then we say 'we had this community project where we planted, like, 200 ' and it's like that's not a big deal. But we can 
say that people came from the local church group or a company or the schools and they put their hands in the ground and really dug in, and in 2 hours we planted these 200 trees, and then people are like 'whoa, 200 trees!' and you're like, 'but no, it's 35000 trees! 200 trees is nothing!' So we're working on how to get the stories aligning with the data, and then when you add it all up you get what we call magic." The point here is that sometimes a story can be told more impactfully using smaller numbers as a starting point to enable an audience to envision what an impact looks like. A number of participants shared this perspective and clarified that the bigger data with which the stories align does not necessarily need to be collected by the food hub, but instead could be drawn from other research or existing literature.

\section{Discussion: Tensions and Opportunities in Food Hub Evaluation}

Our research both confirmed and clarified a number of tensions with respect to evaluating food hubs. Firstly, there is a distinct gap between food hub stakeholders' and advocates' recognition of how important, or even necessary, it is to evaluate food hub activities on one hand and the hubs' actual capacity to conduct robust, ongoing monitoring and evaluation on the other. While our work initially set out to develop a template that food hubs could use to ease their evaluation efforts, results demonstrated that the significant variability within the sector rendered this approach inappropriate. This was particularly true as we utilized the Blay-Palmer et al. (2013) definition of a food hub, which is especially expansive in nature, allowing for inclusion of hubs across Berti \& Mulligan's (2016) spectrum, from more supply-chain oriented models to those focusing more explicitly on sustainability and community development. The challenges we encountered in trying to develop a template of common food hub metrics is consistent with findings by Matson \& Thayer (2013) that highlight the need for context-specific — as opposed to singular-measures of food hub success, and also reflect O'Hara \& Pirog's (2013) more general discussion of the methodological difficulties inherent in local food system evaluation efforts.

The tension between evaluation needs and capacity was evident in all of the food hubs in our study, regardless of structure and underlying goals; however, the sense of urgency to evaluate was especially acute for nonprofit hubs. Indeed, although representatives of for-profit hubs indicated a keen interest in resources that might support their ability to engage in some form of impact assessment, they were not prioritizing evaluation in the same way as their nonprofit counterparts. Rather, they viewed it as something that would be "poignant and relevant" and that they would "love to be able to do more formally" if external resources were available, but it was not something they would prioritize in terms of their own investment of money or labor. By contrast, the nonprofit hubs expressed a clear awareness of their continued dependence on external funding and, in accordance with Newberry and Taylor's (2012) discussion of the relationship between program evaluation and community food actions, viewed effective evaluation as a kind of prerequisite for maintaining such funding. In spite of these findings, there is evidence that even many for-profit food hubs rely at least in part on grant funding even after many years in operation (Colasanti et al., 2018; Rysin \& Dunning, 2016), suggesting that collecting compelling evidence of impacts to support funding applications is in fact important for both for- and nonprofit entities. In addition, the kinds of sectoral research and evaluation efforts conducted in the United States (Colasanti et al., 2018; Fischer et al., 2013; Hardy et al., 2016) and Ontario (Blay-Palmer et al., 2018), as well as individual food hub evaluation stories (see Schmidt et al., 2011) help paint a picture of food hub benefits that can be used to advocate for policy changes (e.g., public procurement of local food) as well as to push for shifts in consumer purchasing behaviors, both of which benefit food hubs across the definitional spectrum. Being able to point to studies such as these highlights the value of externally conducted research on food hubs, as the resources and expertise of research-oriented institutions can be leveraged to fill gaps in food hub monitoring and evaluation capacity. This reinforces existing calls to increase research on the food hub sector to help support its long-term viability (LeBlanc et al., 2014; Levkoe et al., 2018; Matson \& Thayer, 2013). 
A second tension elucidated by our research relates, not to the need to evaluate food hubs per se, but rather to the kinds of data that are collected or not through evaluation processes. Specifically, there was a consensus amongst research participants that outcomes tied to the social and/or ecological aspects of their work were considerably more difficult to evaluate than financial or economic indicators. "In terms of dollars of local food bought and sold-that's easy to do" explained one participant, going on to note that "the rest of it" (i.e., broader social and environmental outcomes, including increasing access to healthy food, reducing food miles, and supporting ecological farming practices) remained a bit of a mystery. The challenges inherent in measuring the social and ecological, along with economic, impacts of food hub work mirror the struggle that many hubs face in actually doing activities that prioritize social or ecological outcomes over economic ones and, particularly, maintaining those activities over the long term. While not every food hub includes social or environmental goals as part of its mandate, there is evidence that social considerations such as food security, racial equity, access to healthy food, and fair prices for farmers are important for many hubs, as are environmental issues, particularly support for sustainable agricultural practices (see Blay-Palmer et al., 2018; Colasanti et al., 2018). However, the literature also highlights how food hubs' social and/or environmental goals are often subsumed by financial considerations (see Clark et al., 2019; Cleveland et al., 2014; Franklin et al., 2011; Hoey et al., 2018), as evidenced in the headline of a report on food hub closures: "Kentucky food bub suffered when it emphasized social mission over financial viability" (Brislen et al., 2017). As Hoey et al. (2018) explain, food hubs "may be one means of increasing affordable, healthy food access in certain scenarios, but it may be unrealistic and unsustainable for many to prioritize local sourcing, farm viability, and equitable food access simultaneously - unless they can figuratively 'put on their own mask before helping others,' ensuring their own financial stability" (p. 56). At the heart of this difficulty is the fact that, like other local food efforts, food hubs continue to be embedded within a conventional capitalist system that emphasizes eco- nomic performance above social or ecological concerns (Cleveland et al., 2014; Hoey et al., 2018; Stroink \& Nelson, 2013).

In the face of such deeply entrenched structural issues, conducting robust evaluation of food hubs' multidimensional impacts is certainly no silver bullet; however, building capacity for food hubs to effectively identify and articulate their impacts across economic, social, and ecological spheres does represent an opportunity to reduce the vulnerability of individual hubs and strengthen the sector as a whole. For individual food hubs, engaging in some combination of formative (process-oriented, assessing program success) and summative (outcome-oriented, assessing program impacts) evaluation work (see Briedenham \& Butts, 2005) creates important opportunities to clarify vision, ensure strategic alignment between goals and activities, and identify successes as well as areas for improvement. When describing evaluations with a strong process focus, one research participant explained that the results can be used as a kind of "road map," helping ensure that food hubs avoid making detours that leave them stretched beyond capacity and at risk of the kind of failure described by Brislen et al. (2017) and Stroink and Nelson (2013). Beyond these internal uses, food hubs can use more outcome-focused evaluation results to communicate a compelling story about the complex, multidimensional impacts of their work to a variety of audiences. This is particularly important given many hubs' continued reliance, at least in part, on external funding as well as volunteer labor and other donated resources (Hoey et al., 2018; LeBlanc et al., 2014; Stroink \& Nelson, 2013).

While the use of evaluation results to support organizational improvements and secure external funding is of significant practical importance to existing food hub operations, there is a broader argument to be made for identifying and tracking the impacts that food hubs have on the food systems in which they are embedded and that, to varying extents, they seek to transform. Specifically, evaluation has the potential to provide convincing evidence regarding the kinds of public goods that food hubs provide (see Hoey et al., 2018), and that evidence can be used to advocate 
for changes to food system policy. Indeed, a number of our research participants were keenly aware that their evaluation efforts play an instrumental role in increasing their readiness to "get into the political fray" by providing them with solid data regarding the value of their work. In the Canadian context, recent consultations on the development of a national food policy have created opportunities to put this kind of evidence to good use, thus highlighting the importance of such readiness. While policy frameworks still overwhelmingly support the mainstream food system, rendering food hubs and other alternatives at a structural disadvantage, the vulnerabilities of that mainstream food system are becoming ever more apparent (Stroink \& Nelson, 2013), thereby creating some hope that more opportunities to push for policy change may emerge. If food hubs are to be ready for these opportunities, however, it is essential that they have access to resources that facilitate their ability to gather evidence about their impacts.

An additional opportunity that became apparent through our research is for food hubs to look to participatory evaluation models as a means of engaging in action-oriented, collaborative evaluations that can support their own capacity-building, strategic decision-making and growth. As already noted, early research results indicated that developing a process-oriented guide was more realistic, and also more desirable, than establishing a set of common metrics and methods to serve as a onesize-fits-all template for food hub evaluations. To that end, the guide directs users to a variety of resources related to different evaluation steps and styles, including participatory methodologies such as developmental evaluation (see Patton, 1994) and Utilization-Focused Evaluation (see Ramírez \& Brodhead, 2013), that can be adopted and adapted depending on a hub's particular priorities and capacities. These approaches allow for the flexible application of a wide range of data collection methods that can be employed to gather both formative and summative information about an organization's programs and outcomes. They also enable a wide range of stakeholders to participate actively in all phases of an evaluation process and facilitate ongoing practical application of evaluation findings (Crishna, 2007a; Patton, 1994; Ramírez \&
Brodhead, 2013). Conceptualizing evaluation in this way contrasts with more conventional methods, often focused on the logic model. While these methods certainly prove useful in some contexts, and are often incorporated into funding agency requirements, they are also subject to critique for being overly linear, noncollaborative, and more useful to funders than to the organizations or initiatives being funded (see Butterfoss, Francisco, \& Capwell, 2001; Crishna, 2007b). The idea that participatory evaluation approaches are particularly relevant in the context of food hubs builds upon Schmidt et al.'s (2011) case study of the Intervale Food Hub, which underscored the importance of a participatory orientation to food hub research and evoked elements of a developmental evaluation-e.g., supporting the development of an innovative program in an adaptive context, nurturing learning for the organization being evaluated, situating the evaluator as part of a collaborative team that includes program staff (Patton, 1994)—without explicitly defining itself as such. It is also aligned with Meter's (2010) call for assessments that take into account the complex, adaptive nature of food systems (see also Stroink \& Nelson, 2013) and "look for patterns of emergence, rather than relying solely on comprehensive counts of inputs and outputs" (p. 25).

Although we consider the use of participatory evaluation methodologies an opportunity for food hubs, it is also important to recognize that a hub's capacity to employ such methodologies is subject to many of the same resource constraints that hamper any evaluation effort. Indeed, Crishna (2007a) stresses that participatory evaluation strategies require significant time as well as skill-building on the part of participants, and also depend upon availability of a highly trained, creative facilitator. Beyond that, they tend to generate high volumes of data that can be challenging to manage (Butterfoss et al., 2001; Gamble, 2008; Zukoski \& Luluquisen, 2002). Given that many food hubs have been found to overextend themselves to the point of threatening their viability, particularly in the early years (Feldstein \& Barham, 2017; Stroink \& Nelson, 2013), embarking upon a full-fledged participatory evaluation project may not be realistic. However, drawing upon participatory evalua- 
tion methodologies can help hubs in their strategic planning processes, which can in turn help them avoid such overextension. For example, looking to the tools and practices associated with UtilizationFocused Evaluation can provide a road map for how a food hub can actively involve staff, clients, program users and other stakeholders in decisions regarding what information should be tracked based upon the outcomes and metrics most aligned with its vision and goals. Involving multiple stakeholders in this way is, again, consistent with Meter's (2010) discussion of effective food system assessment, and creates opportunities for multiple actors to buy into evaluation processes, thus helping ensure such processes will be implemented over the long term and that results will be applied in a meaningful way (Newberry \& Taylor, 2014; Ramírez \& Brodhead, 2013).

\section{Conclusions}

Our research results demonstrated that food hubs very much need to engage in evaluation work, yet often lack the resources to do so. With limited supplies of time and funds and, in many cases, little or no expertise in evaluation methods, food hub actors often find it challenging to know how to most effectively assess the impacts of their work. In spite of these barriers, however, organizations and businesses across the food hub spectrum see clear value in building simple processes into their operations that allow them to evaluate the multifaceted goods they create for people, communities, and food systems. Evaluation results can be used internally as a means of optimizing a hub's opera- tions, and also externally to garner support from funders, clients, partners and, ideally, policy-makers as well as the general public. Tracking basic financial and economic indicators (e.g., profits, dollar value of local food sold) tends to be the easiest place for many food hubs to start with respect to measuring their success; however, finding ways to capture some of the social and ecological impacts that many hubs include within their mandate is an essential element of a truly effective food hub evaluation strategy.

Although the resource constraints that hinder many food hubs' ability to engage in comprehensive_ - or indeed any_ evaluation work might suggest that development of templated metrics and methods to facilitate consistent data collection across the sector would be useful, our research results indicated that this approach, while not without potential value, was subject to significant limitations. Instead, because of the highly complex, dynamic nature of food hub work, participatory evaluation methodologies that are collaborative, flexible, and process-oriented are especially relevant. Such approaches do not offer a uniform set of metrics or methods, but instead are designed to foster engagement of a wide range of actors in developing and adapting methods to suit the everevolving context of a particular initiative or program. Although working from this kind of participatory, collaborative perspective when conducting evaluation is not without its own challenges, it helps to ensure that evaluation results will be put to practical use in strengthening individual food hubs and the sector more broadly.

\section{References}

Allen, P., FitzSimmons, M., Goodman, M., \& Warner, K. (2003). Shifting plates in the agrifood landscape: The tectonics of alternative agrifood initiatives in California. Journal of Rural Studies, 19(1), 61-75. https://doi.org/10.1016/S0743-0167(02)00047-5

Barham, J., Tropp, D., Enterline, K., Farbman, J., Fisk, J., \& Kiraly, S. (2012, April). Regional food hub resource guide. U.S. Department of Agriculture, Agricultural Marketing Service. Retrieved from http://www.ngfn.org/resources/ngfn-database/knowledge/FoodHubResourceGuide.pdf/view

Berti, G., \& Mulligan, C. (2016). Competitiveness of small farms and innovative food supply chains: The role of food hubs in creating sustainable regional and local food systems. Sustainability, 8(7), 616. https://doi.org/10.3390/su8070616

Blay-Palmer, A., Landman, K., Knezevic, I., \& Hayhurst, R. (2013). Constructing resilient, transformative communities through sustainable "food hubs." Local Environment, 18(5), 521-528.

https://doi.org/10.1080/13549839.2013.797156 
Blay-Palmer, A., Nelson, E., Mount, P., \& Nagy, M. (2018). The long and the short of it: Motivations and realities for food hub actors in Ontario, Canada. In A. Kalfagianni \& S. Skordili (Eds.), Localizing global food: Short food supply chains as responses to agri-food system challenges. London: Routledge. https://doi.org/10.4324/9780429449284

Briedenhann, J., \& Butts, S. (2005). Utilization-focused evaluation. Review of Policy Research, 22(2), 221-243. https://doi.org/10.1111/j.1541-1338.2005.00131.x

Brislen, L., Barham, J., \& Feldstein, S. (2017). Kentucky food hub suffered when it emphasized social mission over financial viability. Rural Cooperatives, 84(4), 20-23.

Butterfoss, F. D., Francisco, V., \& Capwell, E. M. (2001). Stakeholder participation in evaluation. Health Promotion Practice, 2(2), 114-119. https://doi.org/10.1177/152483990100200203

Clark, J. K., Rouse, C., Sehgal, A. R., Bailey, M., Bell, B. A., Pike, S. N., Sharpe, P. A., \& Freedman, D. A. (2019). A food hub to address healthy food access gaps: Residents' preferences. Journal of Agriculture, Food Systems, and Community Development, 9(1), 1-10. https://doi.org/10.5304/jafscd.2019.091.010

Cleveland, D. A., Müller, N. M., Tranovich, A. C., Mazaroli, D. N., \& Hinson, K. (2014). Local food hubs for alternative food systems: A case study from Santa Barbara County, California. Journal of Rural Studies, 35, 26-36. https://doi.org/10.1016/j.jrurstud.2014.03.008

Colasanti, K., Hardy, J., Farbman, J., Pirog, R., Fisk, J., \& Hamm, M. W. (2018). Findings of the 2017 national food hub survey. East Lansing, MI: Michigan State University Center for Regional Food Systems \& The Wallace Center at Winrock International. Retrieved from https://www.canr.msu.edu/resources/2017-food-hub-survey

Crishna, B. (2007a). Participatory evaluation (I)-Sharing lessons from fieldwork in Asia. Child: Care, Health and Development, 33(3), 217-223. https://doi.org/10.1111/j.1365-2214.2006.00657.x

Crishna, B. (2007b). Participatory evaluation (II) - Translating concepts of reliability and validity in fieldwork. Child: Care, Health and Development, 33(3), 224-229. https://doi.org/10.1111/j.1365-2214.2006.00658.x

Fagen, M. C., Redman, S. D., Stacks, J., Barrett, V., Thullen, B., Altenor, S., \& Neiger, B. L. (2011). Developmental evaluation: Building innovations in complex environments. Health Promotion Practice, 12(5), 645-650. https://doi.org/10.1177/1524839911412596

Feldstein, S., \& Barham, J. (2017). Running a food bub: Learning from food bub closures (Report No. 77, Vol, 4). U.S. Department of Agriculture, Rural Development.

Fetterman, D. M. (1994). Empowerment evaluation. Evaluation Practice, 15(1), 1-15. https://doi.org/10.1016/0886-1633(94)90055-8

Fischer, M., Hamm, M., Pirog, R., Fisk, J., Farbman, J., \& Kiraly, S. (2013). Findings of the 2013 national food hub survey. East Lansing, MI: Michigan State University Center for Regional Food Systems \& The Wallace Center at Winrock International. Retrieved from https://www.canr.msu.edu/resources/2013-food-hub-survey

Food and Agriculture Organization of the United Nations [FAO]. (2011). The state of the world's land and water resources for food and agriculture (SOL $A W$ ) —Managing systems at risk. Food and Agriculture Organization of the United Nations and Earthscan. Retrieved from http://www.fao.org/3/i1688e/i1688e00.htm

FAO. (2019). The state of the world's biodiversity for food and agriculture. Food and Agriculture Organization Commission on Genetic Resources for Food and Agriculture. Retrieved from http://www.fao.org/state-of-biodiversity-for-food-agriculture/en/

FAO, IFAD, UNICEF, WFP, \& WHO. (2017). The state of food security and nutrition in the world: Building resiliance for peace and food security. Rome: FAO. Retrieved from https://www.wfp.org/publications/2017-state-food-security-and-nutrition-world-sofi-report

Franklin, A., Newton, J., \& McEntee, J. C. (2011). Moving beyond the alternative: Sustainable communities, rural resilience and the mainstreaming of local food. Local Environment, 16(8), 771-788. https://doi.org/10.1080/13549839.2011.574685

Freedgood, J., Pierce-Quiñonez, M., \& Meter, K. (2011). Emerging assessment tools to inform food system planning. Journal of Agriculture, Food Systems, and Community Development, 2(1), 83-104. https://doi.org/10.5304/jafscd.2011.021.023

Gamble, J. A. A. (2008). A developmental evaluation primer. Montréal, CA: J.W. McConnell Family Foundation. Retrieved from https://mcconnellfoundation.ca/report/developmental-evaluation-primer/ 
Hardy, J., Hamm, M., Pirog, R., Fisk, J., Farbman, J., \& Fischer, M. (2016). Findings of the 2015 national food bub survey. East Lansing, MI: Michigan State University Center for Regional Food Systems \& The Wallace Center at Winrock International. Retrieved from https://www.canr.msu.edu/resources/2015-food-hub-survey

Hoey, L., Fink Shapiro, L., \& Bielaczyc, N. (2018). "Put your own mask on before helping someone else": The capacity of food hubs to build equitable food access. Journal of Agriculture, Food Systems, and Community Development, 8(3), 41-60. https://doi.org/10.5304/jafscd.2018.083.012

Jablonski, B. B. R., Schmit, T. M., \& Kay, D. (2015). Assessing the economic impacts of food bubs to regional economies: $A$ framework including opportunity cost (No. 250012). IDEAS Working Paper Series. Retrieved from https://ideas.repec.org/p/ags/cudawp/250012.html

LeBlanc, J. R., Conner, D., McRae, G., \& Darby, H. (2014). Building resilience in nonprofit food hubs. Journal of Agriculture, Food Systems, and Community Development, 4(3), 121-135. https://doi.org/10.5304/jafscd.2014.043.005

Levkoe, C. Z., Hammelman, C., Craven, L., Dandy, G., Farbman, J., Harrison, J., \& Mount, P. (2018). Building sustainable communities through food hubs: Practitioner and academic perspectives. Journal of Agriculture, Food Systems, and Community Development, 8(2), 1-16. https://doi.org/10.5304/jafscd.2018.082.008

Matson, J., \& Thayer, J. (2013). The role of food hubs in food supply chains. Journal of Agriculture, Food Systems, and Community Development, 3(4), 43-47. https://doi.org/10.5304/jafscd.2013.034.004

Matson, J., Thayer, J., \& Shaw, J. (2015a). Running a food bub: A business operations guide, (Service Report No. 77, Volume II). Washington, DC: USDA Rural Development.

Matson, J., Thayer, J., \& Shaw, J. (2015b). Running a food hub: Lessons learned from the field, (Service Report No. 77, Volume I). Washington, DC: USDA Rural Development.

Matson, J., Thayer, J., \& Shaw, J. (2016). Running a food bub: Assessing financial viability (Service Report No. 77, Volume III). Washington, DC: USDA Rural Development.

McFadden, D. T., Conner, D., Deller, S., Hughes, D., Meter, K., Morales, A., . . Tropp, D. (2017, March). The economics of local food systems: A toolkit to guide community discussions, assessments, and choices. U.S. Department of Agriculture, Agricultural Marketing Service. Retrieved from https://localfoodeconomics.com/wpcontent/uploads/2017/03/Toolkit-Designed-FINAL-UPDATED-03-7-2017.pdf

Meter, K. (2010). Metrics from the field: Letting food systems emerge. Journal of Agriculture, Food Systems, and Community Development, 1(1), 23-26. https://doi.org/10.5304/jafscd.2010.011.006

Moraghan, M. R. \& Vanderburgh-Wertz, D. (2014). Food bub business assessment toolkit. Bridgeport, CT: Wholesome Wave.

Nelson, E., \& Landman, K. (2015). Evaluating community food hubs: A practical guide. Guelph, ON: Ontario Ministry of Agriculture, Food and Rural Affairs. Retrieved from http://nourishingontario.ca/blog/2015/06/15/evaluating-community-food-hubs-a-practical-guide/

Newberry, J., \& Taylor, A. (2012). Evaluating outcomes of community food actions: A guide. Public Health Agency of Canada. Retrieved from https://sustainontario.com/greenhouse/resource/evaluating-outcomes-of-community-food-actions-a-guide/

Nourishing Communities. (2015). Ontario food hub case studies. Retrieved from http://nourishingontario.ca/ontario-food-hub-case-studies-2015/

O'Hara, S. (2017). The urban food hubs solution: Building capacity in urban communities. Metropolitan Universities, 28(1), 69-93. https://doi.org/10.18060/21477

O’Hara, J. K., \& Pirog, R. (2013). Economic impacts of local food systems: Future research priorities. Journal of Agriculture, Food Systems, and Community Development, 3(4), 1-8. https://doi.org/10.5304/jafscd.2013.034.003

Patton, M. Q. (1994). Developmental evaluation. Evaluation Practice, 15(3), 311-319. https://doi.org/10.1177/109821409401500312

Patton, M. Q. (2000). Utilization-focused evaluation. In D. L. Stufflebeam, G. F. Madaus \& T. Kellaghan (Eds.), Evaluation models: Viewpoints on educational and human services evaluation (pp. 425-438). Netherlands: Springer.

Perret, A., \& Jackson, C. (2015). Local food, food democracy, and food hubs. Journal of Agriculture, Food Systems, and Community Development, 6(1), 7-18. http://dx.doi.org/10.5304/jafscd.2015.061.003

Ramirez, R. \& Brodhead, D. (2013). Utilization focused evaluation: A primer for evaluators. Penang, Malaysia: Southbound. 
Rose, N. (2017). Community food hubs: An economic and social justice model for regional Australia? Rural Society, 26(3), 225-237. https://doi.org/10.1080/10371656.2017.1364482

Rysin, O., \& Dunning, R. (2016). Economic viability of a food hub business: Assessment of annual operational expenses and revenues. Journal of Agriculture, Food Systems, and Community Development, 6(4), 1-14. https://doi.org/10.5304/jafscd.2016.064.002

Schmidt, M. C., Kolodinsky, J. M., DeSisto, T. P., \& Conte, F. C. (2011). Increasing farm income and local food access: A case study of a collaborative aggregation, marketing, and distribution strategy that links farmers to markets. Journal of Agriculture, Food Systems, and Community Development, 1(4), 157-175. https://doi.org/10.5304/jafscd.2011.014.017

Stahlbrand, L. (2017). Can values-based food chains advance local and sustainable food systems? Evidence from case studies of university procurement in Canada and the UK. International Journal of Sociology of Agriculture and Food, 24(1), 77-95. Retrieved from http://www.fao.org/family-farming/detail/en/c/1136554/

Stroink, M. L., \& Nelson, C. H. (2013). Complexity and food hubs: Five case studies from Northern Ontario. Local Environment, 18(5), 620-635. https://doi.org/10.1080/13549839.2013.798635

Vermeulen, S. J., Campbell, B. M., \& Ingram, J. S. I. (2012). Climate change and food systems. Annual Review of Environment and Resources, 37(1), 195-222. https://doi.org/10.1146/annurev-environ-020411-130608

Zukoski, A., \& Luluquisen, M. (2002). Participatory evaluation: What is it? Why do it? What are the challenges? Community-Based Public Health: Policy and Practice, (5), 1-6. PMID: 11982021 